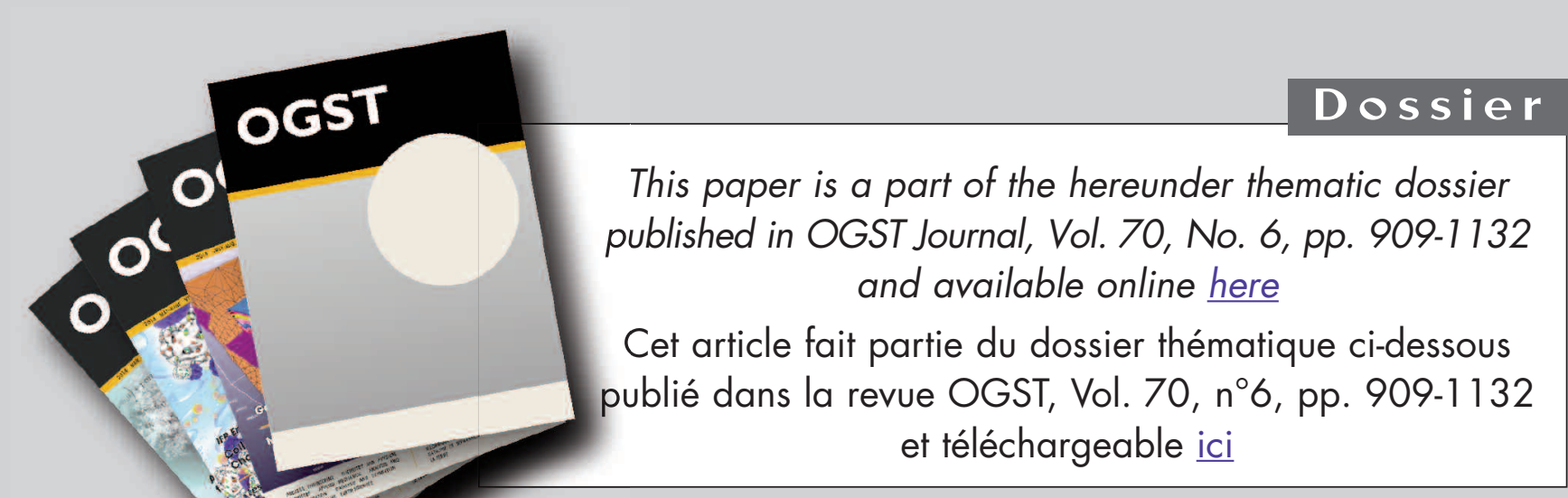

Oil \& Gas Science and Technology - Rev. IFP Energies nouvelles, Vol. 70 (2015), No. 6, pp. 909-1132

Copyright (C) 2015, IFP Energies nouvelles

909 > Editorial - Enhanced Oil Recovery (EOR), Asphaltenes and Hydrates Éditorial - EOR «récupération assistée du pétrole», Asphaltènes et Hydrates D. Langevin and F. Baudin

\section{ENHANCED OIL RECOVERY (EOR)}

917 > HP-HT Drilling Mud Based on Environmently-Friendly Fluorinated Chemicals Boues de forage HP/HT à base de composés fluorés respectueux de I'environnement

I. Henaut, D. Pasquier, S. Rovinetti and B. Espagne

931 > Effective Viscosity in Porous Media and Applicable Limitations for Polymer Flooding of an Associative Polymer

Viscosité effective dans des médias poreux et limites d'application de l'injection de polymères associatifs

P. Zhang, Y. Wang, Y. Yang, W. Chen and S. Bai

$941>$ Dynamic Gelation of HPAM/Cr(III) under Shear in an Agitator and Porous Media Gélification dynamique de HPAM/Cr(III) sous cisaillement dans un agitateur et en milieu poreux

Y. Haiyang, W. Yefei, Z. Jian, L. Peng and S. Shenglong

$951>$ Computer Modeling of the Displacement Behavior of Carbon Dioxide in Undersaturated Oil Reservoirs

Modélisation par ordinateur du comportement de déplacement du dioxyde de carbone dans des réservoirs d'huile non saturés

B. Ju, Y.S. Wu and J. Qin

$967>$ Predicting CO, Minimum Miscibility Pressure (MMP) Using Alternating Conditional Expectation (ACE) Algorithm

Prédiction de la pression miscibilité minimum (MMP) du CO en utilisant un algorithme basé sur l'ACE (Alternating Conditional Expectation)

0 . Alomair, A. Malallah, A. Elsharkawy and M. Iqbal

983 > Towards the Development of Bitumen Carbonates: An Integrated Analysis of Grosmont Steam Pilots

Vers le développement des carbonates bitumineux : une analyse intégrée des pilotes vapeur de Grosmont

C.C. Ezeuko, J. Wang, M.S. Kallos and I.D. Gates

1007> A Novel Model of Foam Flooding Considering Multi-Factors for Enhancing Oil Recovery

Un nouveau modèle d'injection de mousse considérant de multiples facteurs afin d'améliorer la récupération de pétrole

J. Wang, H. Liu, H. Zhang, G. Zhang, P. Liu and K. Sepehrnoori
1025> Testing of Snorre Field Foam Assisted Water Alternating Gas (FAWAG) Performance in New Foam Screening Model

Vérification des performances de la méthode FAWAG (Foam Assisted Water Alternating Gas) sur le champ de Snorre, en Norvège, avec un nouveau modèle de sélection des mousses

P. Spirov and S. Rudyk

\section{ASPHALTENES}

1035> Structural Study of Asphaltenes from Iranian Heavy Crude Oil Étude structurale d'asphaltènes de pétrole brut lourd iranien L. Davarpanah, F. Vahabzadeh and A. Dermanaki

$1051>$ Experimental Study and Mathematical Modeling of Asphaltene Deposition Mechanism in Core Samples

Étude expérimentale et modélisation mathématique du mécanisme de déposition d'asphaltène dans des carottes de forage

T. Jafari Behbahani, C. Ghotbi, V. Taghikhani and A. Shahrabadi

1075> Prediction of the Gas Injection Effect on the Asphaltene Phase Envelope Prévision Prévision de l'effet d'injection de gaz sur l'enveloppe de phase des asphaltènes P. Bahrami, R. Kharrat, S. Mahdavi and H. Firoozinia

\section{HYDRATES}

1087> Methane Hydrate Formation and Dissociation in the Presence of Silica Sand and Bentonite Clay

Formation et dissociation d'hydrates de méthane en présence de sable de silice et d'argile de bentonite

V. Kumar Saw, G. Udayabhanu, A. Mandal and S. Laik

$1101>$ Prediction of Mass Flow Rate in Supersonic Natural Gas Processing Prédiction du débit massique dans les applications de traitement supersonique du gaz naturel

C. Wen, X. Cao, Y. Yang and Y. Feng

$1111>$ Experimental Study on Hydrate Induction Time of Gas-Saturated Water-in-Oil Emulsion using a High-Pressure Flow Loop

Étude expérimentale sur le temps d'induction d'hydrate d'une émulsion eau-enhuile saturée en gaz en utilisant une boucle à circulation sous haute pression X.F. Lv, B.H. Shi, Y. Wang, Y.X. Tang, L.Y. Wang and J. Gong

1125> Hollow Silica: A Novel Material for Methane Storage La silice creuse : un nouveau matériau pour le stockage de méthane V.D. Chari, P.S.R. Prasad and S.R. Murthy 


\title{
Hollow Silica: A Novel Material for Methane Storage
}

\author{
Vangala Dhanunjana Chari ${ }^{1,2}$, Pinnelli S.R. Prasad ${ }^{1 *}$ and Sarabu Ramana Murthy ${ }^{2}$ \\ ${ }^{1}$ Gas Hydrate Group, National Geophysical Research Institute (Council of Scientific \& Industrial Research), Hyderabad - 500007 - India \\ 2 Department of Physics, Osmania University, Hyderabad - 500007 - India \\ e-mail: psrprasad@ngri.res.in \\ * Corresponding author
}

\begin{abstract}
Methane gas storage in the form of Methane Hydrate (MH) in hollow silica was studied and compared with solid silica and pure water systems. The gas hydrate growth/dissociation was monitored by following the pressure (gas intake) - temperature variations in a classical isochoric process. The effect of stirring on the hydrate formation kinetics and yield was clearly evidenced in the case of solid and pure water systems, whereas it did not show any influence in hollow silica; and in fact, the yields remained identical in both stirring and non-stirring experiments. Approximately 3.6 m.mol of methane per gram of water was consumed as $M H$ in the hollow silica matrix and the formation kinetics was extremely fast $(\sim 180 \mathrm{~min})$. However, the methane gas conversion into $\mathrm{MH}$ in solid silica and pure water systems was $\sim 10$ times higher in a stirred reactor when compared with a non-stirred system.
\end{abstract}

Résumé - La silice creuse : un nouveau matériau pour le stockage de méthane - Le stockage de gaz méthane sous la forme d'hydrate de méthane (MH, Methane Hydrate) dans de la silice creuse a été étudié et comparé à un système de silice pleine avec de l'eau pure. La croissance/dissociation de l'hydrate gazeux a été contrôlée en suivant les variations de pression (admission du gaz) et de température dans un processus isochore classique. L'effet de l'agitation sur la cinétique de formation des hydrates et le rendement a été clairement mis en évidence, dans le cas de systèmes d'eau pure et de silice pleine, tandis qu'il ne présente aucune influence dans la silice creuse ; et en fait, les rendements restent identiques à la fois dans des expériences avec agitation et sans agitation. Environ 3,6 m.mol de méthane par gramme d'eau ont été consommés sous forme de $\mathrm{MH}$ dans la matrice de silice creuse et la cinétique de formation a été extrêmement rapide ( $\sim 180 \mathrm{~min})$. Toutefois, la conversion du méthane en $\mathrm{MH}$ dans le système de silice pleine avec de l'eau pure s'est avérée environ 10 fois supérieure dans un réacteur agité par rapport à un système non-agité. 


\section{INTRODUCTION}

Natural gas hydrate, ice like crystalline compound, forms at elevated pressure and in low temperature conditions, in which guest molecules occupy the cages constructed by water molecules through hydrogen bonding. Gas Hydrates (GH) are classified into three different structures, sI, sII and sH, depending on the size of the guest molecules and the shape of the polyhedral water cages [1-3]. The vast occurrences of $\mathrm{GH}$ in the ocean sediments and certain permafrost regions and the present estimations show that their resources are almost double that of all types of available carbon fuels in nature. The interest in the GH is because of the fact that the amount of gas stored in this form is extremely high $(\sim 180$ times STP equivalent). Further, the main constituent in the GH is methane, which is a less polluting and more eco-friendly clean fuel.

This highly dense natural gas in the hydrate form has generated interest in making use of hydrate technology for natural gas storage and transportation [4-6]. However, gas transportation through hydrate technology has to overcome some challenging constraints; among them, a few are the slow hydrate formation rate, the hydrate stability and the low conversion ratio of gas to solid hydrate, resulting in insufficient storage capacity, and the cost involved at various stages of the process. Further, converting the water and gas mixtures into gas hydrates, under suitable thermodynamic conditions, is also an attractive way to store large quantities of gas, such as hydrogen [7, 8] and carbon dioxide [9]. Extensive efforts have been made to develop efficient storage techniques in both scientific and industrial fields. Thus, the research on gas hydrates gained momentum for separating $\mathrm{CO}_{2}$ from flue gases and storing it under ocean floors [10,11].

$\mathrm{GH}$ formation is possible at sub-ambient temperature and high pressure, but these can be altered by adding some additives to the hydrate forming system. In general, it is known that gas hydrate forms on a gas-liquid interface, and thus mainly the gas-liquid interfacial area can affect hydrate formation. Therefore, an efficient way to increase these factors is necessary for forming gas hydrate solid in a gas-liquid system. For example, several processes to increase the gas hydrate formation have been demonstrated. To increase the effective temperature at a specific pressure for hydrate formation, thermodynamic promoters such as THF (Tetra Hydro Furan) were used [12]. However, the disadvantage with such system is a significant decrease in the storage capacity of the fuel gas (guest) molecules due to the fact that part of the hydrate cages are occupied by the promoter guest molecules. The addition of surfactants such as Sodium Dodecyl Sulfate (SDS) can promote the gas hydrate formation without affecting the thermodynamics of hydrate crystallization. SDS accelerates the methane hydrate growth by increasing the total surface area / morphology of hydrate particles and the gas liquid interfacial area. Nevertheless, as the hydrate formation is exothermic, therefore a certain amount of heat is liberated during the hydrate formation [13-14]. A higher amount of such heat could lead to substantial rise in the system temperature and could effectively decrease the growth kinetics. The effect of the heat of hydrate formation on the hydrate growth was lowered by the addition of a small amount of aluminium foam, but at high pressures it has its own limitations [15]. Recently, the use of Dry Water (DW) was reported by Wang et al. [16] to increase the effective interacting area of methane gas molecules with water molecules to achieve high hydrate yield, but the reusability and rigorous preparative conditions associated with the system are the main constraints. Further use of dry gel along with DW offered a limited solution for reusability as the hydrate conversion capability was highly reduced in subsequent freezing and thawing cycles [17].

The literature shows that continuous stirring conditions have a predominant effect on the hydrate nucleation and growth, since the water-gas interfacial area is continuously renewed [18-20]. The induction time depends on the degree of agitation, the presence of foreign particles, and the rate of heat and mass transfer. In the case of hydrate formation in a porous media it is necessary to account for additional forces such as capillary ones during the growth of the hydrate, though in case of stirring these forces are neglected due to continuous agitation in the system. In our previous paper we reported the effect of silica particles on methane hydrate stability and the kinetic promotion behaviour on hydrate formation in a stirred vessel [18]. Even though hydrate yield was lower in silica + water + $\mathrm{CH}_{4}$, the addition of a small amount of silica acts as a kinetic promoter for the formation of MH. Most of the experiments on methane hydrate formation kinetics in sediments are reported in isobaric conditions. The studies on the isochoric cooling process with temperature and pressure both decreasing are scarce. Experimentally the constant gas pressure is maintained in isobaric conditions when the system temperature is within the Gas Hydrate Stability Zone (GHSZ), while in the isochoric process a fixed amount of gas is added to a reactor and the temperature is slowly brought into the GHSZ. In the present paper methane hydrate formation, growth kinetics and hydrate yield in two types of silica systems are reported and compared with a pure water system. The significance of stirring on the methane hydrate formation with different silica systems in an isochoric process in similar $P-T$ conditions is examined. 


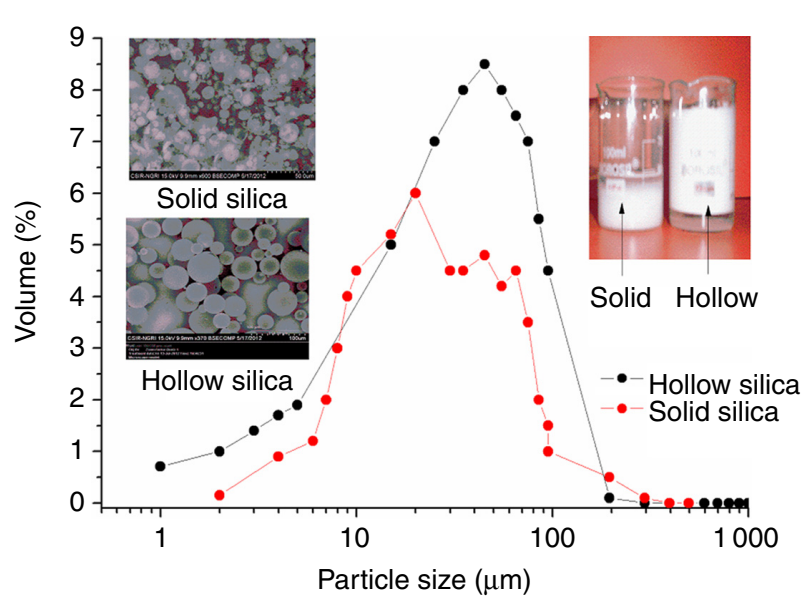

Figure 1

FESEM images and grain size distribution of silica samples used for methane hydrate synthesis.

\section{EXPERIMENTAL SECTION}

\subsection{Materials and Characterization}

The silica powders were obtained from Nanoshel (Intelligent Materials Pvt. Ltd.). Deionized ultra-pure water (Millipore - type 1) was used, and dissolved gases were removed by evacuation. The methane gas used was $99.95 \%$ pure. In Figure 1 we show the grain size distribution and the morphology of the silica. The morphology of the silica, analyzed by a Field Emission Scanning Electron Microscope (FESEM Carl Zeiss Ultra 55), shows that the silica particles are spherical with a mean diameter of 30-80 $\mu \mathrm{m}$ (inset figures). The grain size distribution was measured by the Dynamic Light-Scattering (DLS) method in a water suspension using a particle size analyzer (Malvern Mastersizer 2000), and the maximum volume of particles was in a particle size range of 20-90 $\mu \mathrm{m}$. The bulk density of hollow silica was measured as $0.10 \mathrm{~g} . \mathrm{cm}^{-3}$, while the same for solid silica having similar particle size distributions was $1.5 \mathrm{~g} . \mathrm{cm}^{-3}$. The BET specific surface area of the hollow silica was $2.4 \mathrm{~m}^{2} \cdot \mathrm{g}^{-1}$. For the experimental studies, we used the same amounts of silica $(12.5 \mathrm{gm})$ and water $(100 \mathrm{~mL})$ in the solid and hollow systems. In the inset of Figure 1 we show that the solid silica was settled at the bottom of the water column, whereas the hollow silica was floating on the water with some amount of water trapped (we used $\sim 10 \mathrm{~g}$ of silica and the water was $50 \mathrm{~mL}$ ) [21] in the pore spaces and between the voids of hollow silica particles.

\subsection{Apparatus and Procedure}

The main part of the apparatus is a SS-316 cylindrical vessel, which can withstand pressures up to $10 \mathrm{MPa}$, and the volume of the vessel is $250 \mathrm{~mL}$. The silica powders were used as such and the required amounts of silica and degassed ultra-pure water were measured by using a Metler Toledo (AB104-S) accurate analytical balance. Cold fluid (water + glycol mixture) circulated around the vessel with the help of a circulator (coolant temperature was kept at $275 \mathrm{~K}$ ) to maintain the temperature inside the cell $(\sim 277 \mathrm{~K})$ at the desired level. A platinum resistance thermometer (Pt100) was inserted into the vessel to measure temperatures with an accuracy of $\pm 0.2 \mathrm{~K}$. The pressure in the vessel was measured with a pressure transducer (WIKA, type A-10 for pressure range $0-25 \mathrm{MPa}$ with \pm 0.5 accuracy). A stirrer with variable speed was installed in the vessel to agitate the fluids. The effect of the stirring rate on methane hydrate formation was studied by Vysniauskas and Bishnoi [22], and it was observed that at lower rpm (less than 300) the hydrate crystals tended to remain on the surface, and at least $400 \mathrm{rpm}$ was required to remove the hydrate crystals from the surface. Also, the studies of Golombok et al. [23], revealed that the induction time was dependent on the stirrer rpm and induction times can be brought down by increasing the stirring rates. However, higher rpm $(\sim 800)$ decreases the induction time but at the cost of a decrease in the hydrate yield [20]. Therefore, all the stirred experiments were conducted with a fixed speed of $500 \mathrm{rpm}$. The methane gas was supplied from a cylinder to the desired level (7.5-10 MPa) using a Teledyne ISCO Syringe pump. After obtaining the temperature and pressure stability far above the hydrate formation region, the valve inline connecting the vessel and the ISCO pump/cylinder was closed. Subsequently, the cold fluid from the chiller was circulated and the hydrate formation in the vessel at a particular temperature was detected by a sharp pressure drop. The insignificant head-pressure drop in the reactor over longer duration indicates the saturation of hydrate conversion. After the completion of hydrate conversion, if the temperature is increased stepwise to bring the system out of the hydrate forming region, hydrate crystals partially dissociate, thereby substantially increasing the pressure. The temperature and pressure were logged at 60 -second time intervals. In this way, a pressure temperature diagram (cooling and warming) was obtained for each experimental run, from which we determined the hydrate formation and dissociation pattern. In the case of the non-stirred system the water + silica were mixed and agitated with a glass rod by hand only; no vigorous mixing was applied as in the case 


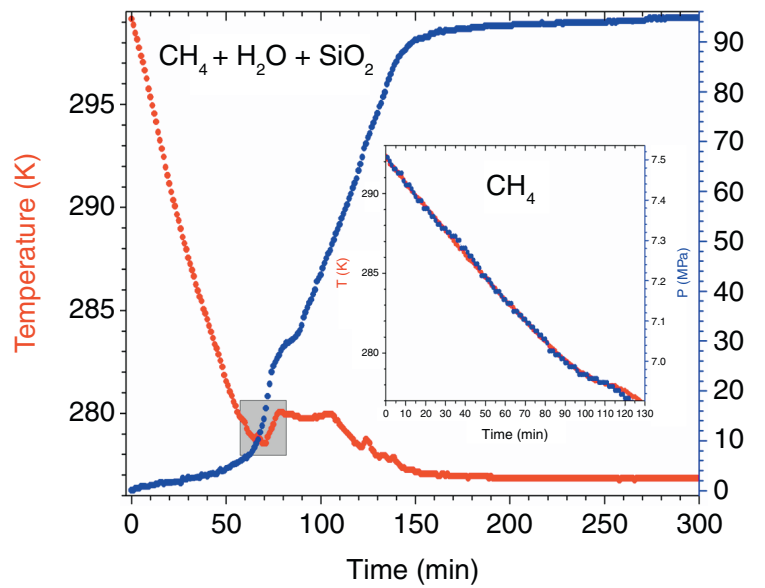

Figure 2

Observed temporal variations of temperature and methane gas consumption (calculated from Eq. 1) in the silica + water $+\mathrm{CH}_{4}$ system during the cooling cycle. In the inset, we show time variations of gas pressure and temperature for $\mathrm{CH}_{4}$ (methane gas without water).

of the DW system. The molar concentration of methane gas $(\Delta n \mathrm{H}, t)$ in the hydrate phase during the experiment is defined by the following equation [21]:

$$
\Delta n \mathrm{H}, t=n \mathrm{~g}, 0-n \mathrm{~g}, t=\left(P_{0} V / Z_{0} R \mathrm{~T}_{0}\right)-\left(P_{t} V / Z R \mathrm{~T}_{t}\right)
$$

where $Z$ is the compressibility factor calculated by the Peng-Robinson equation of state. The gas volume $(V)$ was assumed to be constant during the experiments, i.e., the volume changes due to phase transitions were neglected. $n \mathrm{~g}, 0$ and $n \mathrm{~g}, t$ represent the number of moles of feed (methane) gas taken at zero time and in the gas phase at time $t$, respectively ( $n$ represents the number of moles of feed gas). The hydrate yield was computed from the observed methane gas consumption to the expected values with ideal stoichiometry compositions $\left(8 \mathrm{CH}_{4} \cdot 46 \mathrm{H}_{2} \mathrm{O}\right)^{1}$.

\section{RESULTS AND DISCUSSION}

In Figure 2, we show the temporal variations in the recorded temperature and gas consumption for: $\mathrm{CH}_{4}$ $+\mathrm{H}_{2} \mathrm{O}+\mathrm{SiO}_{2}$ (hollow) in a continuously stirred reactor vessel. In the inset, we also show a plot for temporal

\footnotetext{
${ }^{1}$ Yield $=$ (observed mass ratio) $/($ expected mass ratio $)$. The mass of methane gas consumed $\left(\mathrm{mCH}_{4}\right)$ is calculated from the observed pressure drop during $\mathrm{MH}$ formation. Observed:

$$
\text { weight ratio }=\frac{\left(m \mathrm{CH}_{4}\right)}{\left(m \mathrm{CH}_{4}+m \mathrm{H}_{2} \mathrm{O}\right)} ;
$$

expected:

$$
\text { weight ratio }=\frac{\left(8 \times \text { molar mass of } \mathrm{CH}_{4}\right)}{\left(8 \times \text { molar mass of } \mathrm{CH}_{4}+46 \times \text { molar mass of } \mathrm{H}_{2} \mathrm{O}\right)} \text {. }
$$
}
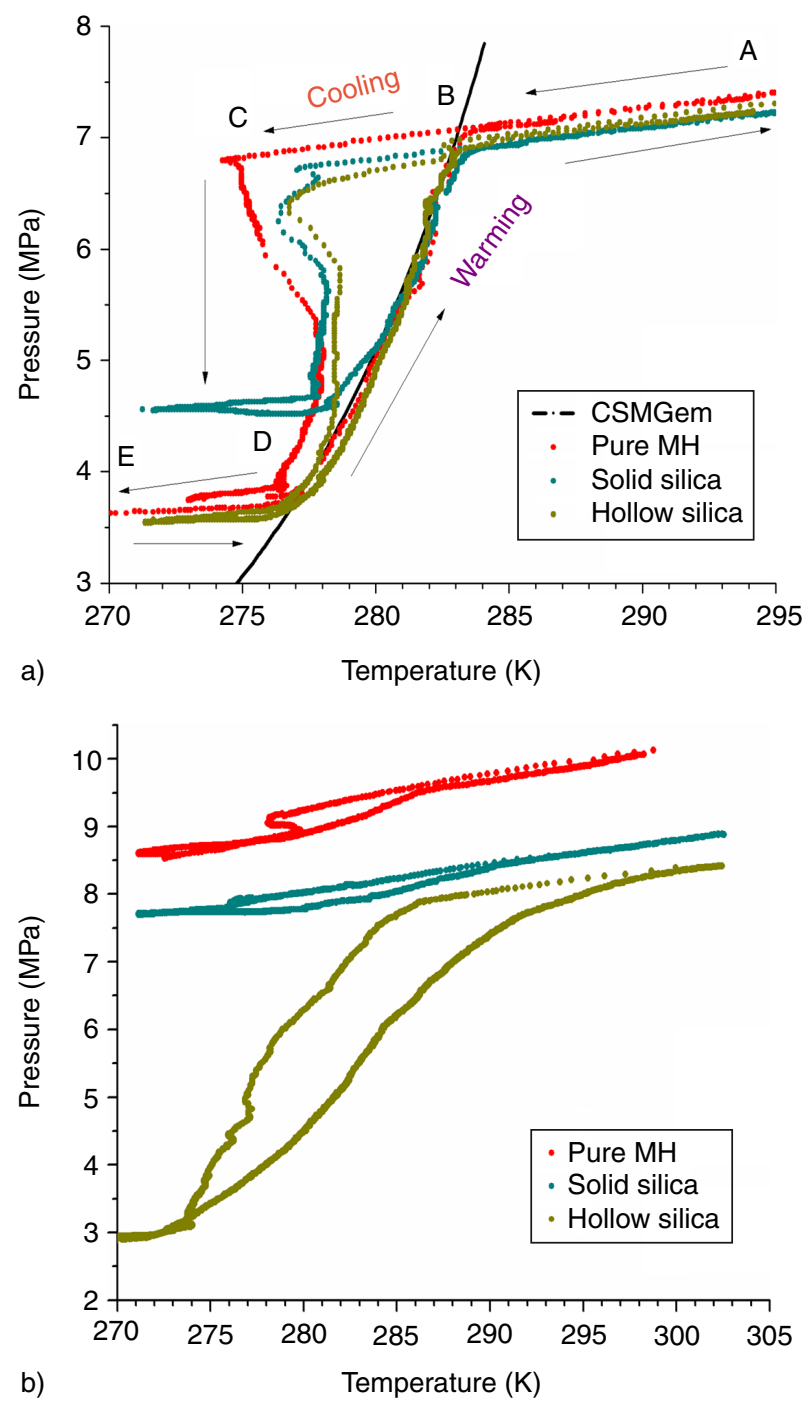

Figure 3

The pressure-temperature trajectories of formation and dissociation of methane hydrate synthesized in a stirred (a) and non-stirred (b) reactor.

variations in the temperature and pressure of $\mathrm{CH}_{4}$ gas alone as a control experiment. From the inset it is clearly seen that the pressure and temperature decrease progressively with time during the cooling process, indicating real gas behaviour, whereas when water (an essential constituent for gas hydrates) is also present along with the methane, a much more rapid decrease in the vapor state pressure (Fig. 3) or much more rapid consumption of gas (Fig. 2), indicates the hydrate formation. Further, a smaller pressure drop (0.8 $\mathrm{MPa}$ in the temperature range of $298-277 \mathrm{~K}$ ) is due to a temperature decrease, which is due to methane gas dissolution in 
water and the compressibility of methane gas in the reactor. However, a much sharper pressure drop in the narrow temperature zone, as shown in the $p$ - $T$ trajectories (Fig. 3), clearly indicates the hydrate formation. During the first $50 \mathrm{~min}$ in the case of $\mathrm{CH}_{4}+\mathrm{H}_{2} \mathrm{O}$ present with $\mathrm{SiO}_{2}$, the system entered into the GHSZ and as hydrate formation is an exothermic phenomenon, a small rise in temperature $(283 \mathrm{~K}$ at $7 \mathrm{MPa}$, Fig. 3) indicates the hydrate nucleation in the system. We also noted that a considerable rise in the temperature ( 278 to $280 \mathrm{~K}$ ) indicates the growth of the hydrate (shown as a shaded square). The pressure drop was around $1.5 \mathrm{MPa}$ in the temperature range of 282-279 K. Further, it took about 70 min to complete the hydrate formation and to reach equilibrium temperature. Thereafter there is no measurable pressure decrease for a longer time, indicating the saturation of hydrate formation.

In Figure 3, we show the MH formation and dissociation with constant stirring (500 rpm) $[20,22,23]$ and without stirring. The points $\mathrm{A}, \mathrm{B}, \mathrm{C}$ and $\mathrm{D}$ marked in the $p$ - $T$ trajectory (Fig. $3 a$ ) show observed variations during hydrate formation and dissociation. The point A (starting point) is clearly outside the GHSZ, whereas points $\mathrm{B}$ and $\mathrm{D}$ are on the phase stability curve, and point $\mathrm{C}$ is inside the GHSZ. A slow decrease in the pressure with temperature in the A-B-C region indicates the dissolution of methane gas in water. The portion $\mathrm{BC}$ signifies the super-cooled state of the reaction mixture without nucleation of hydrate particles even though the pressure and temperature are conducive for hydrate formation. The system requires some amount of sub-cooling for hydrate nucleation and growth. The temperature difference between the temperature at point $\mathrm{B}$ called equilibrium temperature $\left(T_{\text {eqm }}\right)$ and that at point $\mathrm{C}$ is called the sub-cooling $\left(T_{\text {sub }}\right)$, where $T_{\text {sub }}=T_{\text {eqm }}(\mathrm{B})-T(\mathrm{C})$, and the time required to reach $\mathrm{C}$ from $\mathrm{B}$ is called induction time [2]. By retaining the system there for some more time, a small but noticeable temperature rise in the hydrate forming system indicates the nucleation of hydrates. Afterward, a small decrease in the temperature (C to $\mathrm{D})$ results in a rapid decrease in the gas pressure, which indicates the growth of hydrates. This process continues for some time, after which the pressure-temperature variations are marginal (D to E), signifying the saturation of hydrate conversion. A similar pattern is also observed in the warming cycle. The phase change of methane gas and liquid water into the solid gas hydrate is typically a first-order transition, and thus, occurs with a finite hysteresis loop. Even though the hysteresis loop area depends on other factors such as the rate of temperature variations, typically this is cor related with the volume fraction of the hydrates at constant temperature variations [24]. It is well known that undercooling significantly depends on the sediment matrix and also depends on the particle size [25]. It is observed from Figure $3 a, b$ that in stirred and nonstirred systems, pure methane hydrates require more undercooling to form hydrates when compared with a silica + water $+\mathrm{CH}_{4}$ system. Moreover, the experimental $p$ - $T$ trace shows that the pressure drop in the case of hollow silica is maximum in stirred and non-stirred systems, indicating the gas conversion to hydrate differs in the two different types of silica systems. Even though in a stirred system, the methane gas conversion into hydrates in the case of solid silica is significant, it is low when compared with the other two systems. Approximately the same amount of methane is consumed in pure and hollow silica. In the case of the non-stirred system, during the cooling process, the pressure drop is very small for water $+\mathrm{CH}_{4}$, solid silica + water $+\mathrm{CH}_{4}$ and the drop in pressure is approximated to the real gas law with very low methane gas to methane hydrate conversion (20-30 m.moles). Though a high driving force favours more hydrate yield [27], we did not observe any increase in the pressure drop even at high pressures in case of water $+\mathrm{CH}_{4}$, solid silica + water $+\mathrm{CH}_{4}$. By contrast, as shown in figure $3 b$, the $\mathrm{MH}$ formation occurred and there is a substantial $\mathrm{MH}$ growth in the case of the hollow silica system. A dramatic pressure drop upon cooling and a rapid pressure rise upon heating are noted.

From some previous reports the role of stirring in improved kinetics for hydrate formation was clearly evidenced [18-20], as the stirring is very useful to renew the contact surface between the liquid and gas phases, thus preventing the formation of a solid crust at the interface. The heat and mass transfer scenarios were different in both stirred and non-stirred systems and play a significant role in the hydrate nucleation, the induction time and the growth of the hydrate after nucleation [28]. Therefore, in the case of the non-stirred system, the sub-cooling $\left(\sim \Delta t=5^{\circ}-8^{\circ}\right)$ required was found to be different when compared with stirring, for which undercooling was approximately the same with a marginal difference of $2-3^{\circ}$. It was interesting to note that in the case of non- stirred hollow silica system, the hydrate growth started as the system just entered into the hydrate forming region (GHSZ, Fig. 3b), showing no requirement of sub-cooling.

In order to accelerate the formation of methane hydrate, the enhancement of gas-water contacts and hydration heat removal are two crucial approaches. As reported in the literature [13, 14], the addition of SDS to water increases the gas hydrate formation rate and storage capacity. However, fast hydrate formation is 

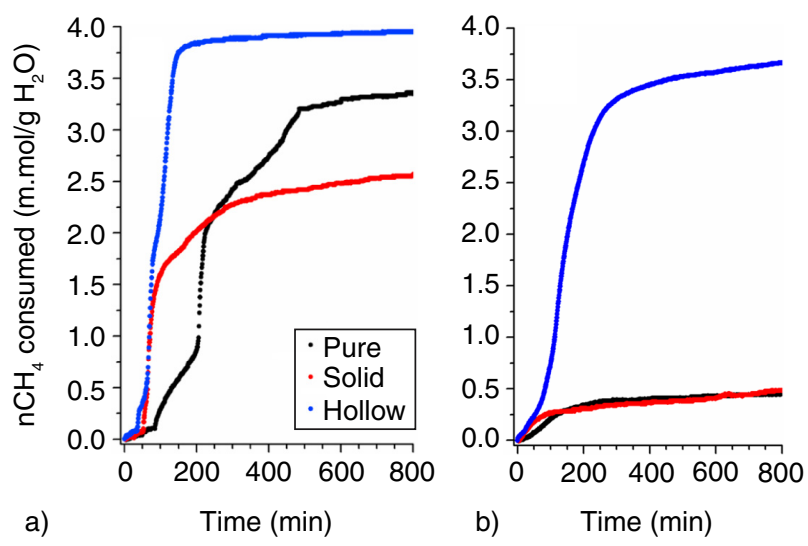

Figure 4

Methane hydrate formation kinetics in pure, solid and hollow silica systems (a- stirred and b- non-stirred).

always associated with the generation of great hydration heat, that weakens the acceleration effect of SDS on hydrate formation. According to Liang et al. [15], aluminum foam (AF) is an excellent thermal conductor possessing good thermal conductivity and a large rough surface. When AF combined with SDS is used as the additive, they observed faster formation and growth of methane hydrate, reducing the effect of the heat of hydrate formation; however, this system has some limitations. As mentioned above from the literature it is very clear that the methane gas uptake and the induction time were considerably reduced in the stirred tank reactor. At different locations in the system, once the critical hydrate nucleus size was reached then rapid hydrate growth occurred. The method followed to calculate the amount of methane gas consumed in the form of hydrate and the hydrate yield calculations are given elsewhere [18].

The reports of Linga et al. [28] show that during the initial stage of hydrate growth in sand systems, the stirring dominated, but later on it had less effect on hydrate conversion when compared with a non-stirred system. Over longer time scales, the methane gas convertion to methane hydrate (hydrate yield) was found to be greater in the case of non-stirred system. When it comes to fuel gas transportation in the form of hydrates, hydrate yield as well as the formation kinetics are both important. From Figures $4 a, b$, the formation kinetics was very much quicker in hollow silica in the case of stirred and non-stirred systems. The conversion kinetics of $\mathrm{CH}_{4}$ gas to $\mathrm{MH}$ was also faster than that of the aforementioned reference [27] with less hydrate yield. For the hollow silica system, the time required to bring the system into the GHSZ in both the cases before the nucleation was about ( $\sim 40$ to $45 \mathrm{~min})$. After the nucleation the average hydrate growth rate was around: $0.0542 \mathrm{~m} . \mathrm{mol} / \mathrm{g} . \mathrm{H}_{2} \mathrm{O} / \mathrm{min}(50-120 \mathrm{~min})$ in stirred and $0.0216 \mathrm{~m} \cdot \mathrm{mol} / \mathrm{g} \cdot \mathrm{H}_{2} \mathrm{O} / \mathrm{min}(50-200 \mathrm{~min})$ in nonstirred systems. The time required for $90 \%$ conversion of methane gas to hydrate, from the start of the experiment, was found to be around 250 minutes (non-stirred) and only 120 minutes in the case of the stirred system. The experiments were repeated at least five times and we found there was an infinitesimal change in the hydrate conversion factor.

The effect of stirring on methane hydrate formed in hollow silica was completely absent, as the kinetics and hydrate yield were the same in both cases. From Figures $4 \mathrm{a}, \mathrm{b}$, the slope variations during the hydrate growth in the case of hollow silica (stirred) were assumed to be due to the heat and mass transfers; it was due to gas diffusion and capillary force in the case of the non-stirred system. In Table 1, we show the details of the number of moles of $\mathrm{CH}_{4}$ gas converted to hydrate in stirred and non-stirred reactors. The kinetics and hydrate yield (the methane gas storage capacity) in different silica systems confirm that the hollow silica has an anomalous behavior in stirred and non-stirred systems. With advantages such as an increase in the hydrate growth kinetics without any stirring and high hydrate yield, the hollow silica system could definitely

TABLE 1

The methane gas consumed in hydrate formation in the case of pure and different types of silica systems in non-stirred and stirred systems

\begin{tabular}{l|c|c|c|c|c}
\hline S. No & System & $\begin{array}{c}n \mathrm{CH}_{4} \text { consumed } \\
\left(\mathrm{m} . \mathrm{mol} / \mathrm{g} . \mathrm{H}_{2} \mathrm{O}\right)(\text { stirred) }\end{array}$ & $\begin{array}{c}\text { Hydrate yield }(\%) \\
\text { (stirred) }\end{array}$ & $\begin{array}{c}n \mathrm{CH}_{4} \text { consumed } \\
\left(\mathrm{m} . \mathrm{mol} / \mathrm{g} . \mathrm{H}_{2} \mathrm{O}\right)(\text { non-stirred) }\end{array}$ & $\begin{array}{c}\text { Hydrate yield }(\%) \\
(\text { non-stirred })\end{array}$ \\
\hline 1 & Pure MH & $3.48( \pm 0.11)$ & $39.21( \pm 1.07)$ & $0.30( \pm 0.07)$ & $3.60( \pm 0.51)$ \\
\hline 2 & Solid silica & $2.80( \pm 0.12)$ & $31.34( \pm 0.95)$ & $0.32( \pm 0.05)$ & $3.80( \pm 0.62)$ \\
\hline 3 & Hollow silica & $4.09( \pm 0.21)$ & $43.22( \pm 1.90)$ & $3.89( \pm 0.23)$ & $43.69( \pm 1.7)$ \\
\hline
\end{tabular}


be considered as a useful system for methane gas storage and transport applications in the hydrate form.

\section{CONCLUSION}

We studied methane hydrate formation and the effect of stirring in two different types of silica systems and compared them with the pure MH system. Significant methane hydrate formation was observed in all systems when stirring was employed. The methane gas conversion to MH was found to be minimum in solid silica and maximum in hollow silica. However, in the case of the nonstirred reactor, the hydrate yield was almost negligible in pure/solid silica when compared with hollow silica. In hollow silica, the methane hydrate formation kinetics and the methane gas to $\mathrm{MH}$ conversion were the same as those of the stirred system, showing no effect of stirring. The type of silica (solid or hollow) plays an important role in hydrate conversion. The fast hydrate formation kinetics and high hydrate yield without stirring in the hollow silica system effectively reduce the cost of hydrate synthesis. Therefore, hollow silica is a viable platform for the storage and transportation of methane gas in the form of $\mathrm{MH}$.

\section{ACKNOWLEDGMENTS}

The authors acknowledge the funding from the Council for Scientific and Industrial Research, Department of Science \& Technology, Ministry of Earth Sciences (Gas Hydrates program) and the Directorate of Hydrocarbons (NGHP), Government of India, through sponsored projects. The authors sincerely thank the Director of the National Geophysical Research Institute, Hyderabad, for his encouragement, and permission to publish this paper.

\section{REFERENCES}

1 Englezos P. (1993) Clathrate Hydrates, Ind. Eng. Chem. Res. 32, 1251-1274.

2 Sloan E.D., Koh C.A. (2008) Clathrate Hydrates of Natural Gases, 3rd ed., CRC Press, Taylor \& Francis Group, Boca Raton.

3 Sloan E.D. (2003) Fundamental principles and applications of natural gas hydrates, Nature 426, 353-359.

4 Makogon Y.F., Holditch S.A., Makogon T.Y. (2007) Natural gas-hydrates - A potential energy source for the 21st Century, J. Pet. Sci. Eng. 56, 14-31.

5 Gudmundson J.S., Parlaktuna M., Levik O.I., Andersson V. (2000) Laboratory for Continuous Production of Natural Gas Hydrates, Ann. New York Aca. Sci. 912, 851-858.
6 Daimaru T., Fujii M., Yamasaki A., Yanagisawa Y. (2004) Energy saving potential for natural gas hydrate transportation, Prepr. Pap.-Am. Chem. Soc., Div. Fuel Chem. 49, 190191.

7 Prasad P.S.R., Sugahara T., Sum A.K., Sloan E.D., Koh C. A. (2009) Hydrogen Storage in double clathrates with tertbutylamine, J. Phys. Chem. A. 113, 6540-6453.

8 Sugahara T., Haag J.C., Prasad P.S.R, Warntjes A.A., Sloan E.D., Sum A.K., Koh C.A. (2009) Increasing hydrogen storage capacity using tetrahydrofuran, J. Am. Chem. Soc. 131, 14616-14617.

9 Linga P., Kumar R., Englezos P. (2007) The clathrate hydrate process for post and pre-combustion capture of carbon dioxide, J. Hazard. Mater. 149, 625-629.

10 Kang S.P., Lee J., Seo Y. (2013) Pre-combustion capture of $\mathrm{CO}_{2}$ by gas hydrate formation in silica gel pore structure, Chem. Eng. J. 218, 126-132.

11 Babu P., Kumar R., Linga P. (2013) A New Porous Material to Enhance the Kinetics of Clathrate Process: Application to Precombustion Carbon Dioxide Capture, Env. Sci. Tech. 47, 13191-13198.

12 Chari V.D., Sharma D.V.S.G.K., Prasad P.S.R. (2011) Methane hydrate phase stability with lower mole fractions of tetrahydrofuran (THF) and tert-butylamine $\left(\mathrm{t}-\mathrm{BuNH}_{2}\right)$, Fluid Phase Equilib. 315, 126-130.

13 Zhong Y., Rogers R.E. (2000) Surfactant effects on gas hydrate formation, Chem. Eng. Sci. 55, 4175-4187.

14 Ganji H., Manteghian M., Zadeh K.S., Omidkhah M.R., Mofrad H.R. (2007) Effect of different surfactants on methane hydrate formation rate, stability and storage capacity, Fuel 86, 434-441.

15 Liang Y., Shuanshi F., Wang Y., Xuemei L., Xie D. (2011) Accelerated Formation of Methane Hydrate in Aluminum Foam, Ind. Eng. Chem. Res. 50, 11563-11569.

16 Wang W., Bray C.L., Adams D.J., Cooper A.I. (2008) Methane Storage in Dry Water Gas Hydrates, J. Am. Chem. Soc. 130, 11608-11609.

17 Carter B.O., Wang W., Adams D.J., Cooper A.I. (2010) Gas Storage in "Dry Water" and "Dry Gel" Clathrates, Langmuir 26, 3186-3193.

18 Prasad P.S.R., Chari V.D., Sharma D.V.S.G.K., Murthy S.R. (2012) Effect of silica particles on the stability of methane hydrates, Fluid Phase Equilib. 318, 110-114.

19 Mork M., Gudmundsson J.S. (2002) Hydrate Formation Rate in a Continuous Stirred Tank Reactor: Experimental Results and Bubble-to-Crystal Model, 4th International Conference on Gas Hydrates.

20 Wenfeng H., Wang J., Shuanshi F., Wenbin H. (2007) Study on methane hydration process in a semi-continuous stirred tank reactor, Energy Convers. Manage 48, 954-960.

21 Chari V.D., Raju B., Prasad P.S.R., Rao D.N. (2013) Methane hydrates in spherical silica matrix: Optimization of capillary water, Energy Fuels 27, 3679-3684.

22 Vysniauskas A., Bishnoi P.R. (1983) A kinetic study of methane hydrate formation, Chem. Eng. Sci. 38, 1061-1972.

23 Golombok M., Ineke E., Luzardo J.C.R., He Y.Y., Zitha P. (2009) Resolving $\mathrm{CO}_{2}$ and methane hydrate formation kinetics, Envi. Chem. Lett. 7, 325-330. 
24 Anderson R., Tohidi B., Webber J.B.W. (2009) Gas hydrate growth and dissociation in narrow pore networks: capillary inhibition and hysteresis phenomena, The Geological Society, London, Special Publications 319, 145-159.

25 Guanli J., Qingbai W., Jing Z. (2010) Effect of cooling rate on methane hydrate formation in media, Fluid Phase Equilib. 298, 225-230.

26 Chari V.D., Sharma D.V.S.G.K., Prasad P.S.R., Murthy S. R. (2013) Methane hydrates formation and dissociation in nano silica suspension, J. Nat. Gas Sci. Eng. 11, 7-11.
27 Linga P., Daraboina N., Ripmeester J.A., Englezos P. (2012) Enhanced rate of gas hydrate formation in a fixed bed column filled with sand compared to a stirred vessel, Chem. Eng. Sci. 68, 617-623.

Manuscript accepted in March 2014 Published online in July 2014

Cite this article as: V.D. Chari, P.S.R. Prasad and S.R. Murthy (2014). Hollow Silica: A Novel Material for Methane Storage, Oil Gas Sci. Technol 70, 6, 1125-1132. 